\title{
Enterococcus faecium: from microbiological insights to practical recommendations for infection control and diagnostics
}

\author{
Xuewei Zhou ${ }^{1 *}$ (D), Rob J. L. Willems², Alexander W. Friedrich', John W. A. Rossen and Erik Bathoorn ${ }^{1}$
}

\begin{abstract}
Early in its evolution, Enterococcus faecium acquired traits that allowed it to become a successful nosocomial pathogen. E. faecium inherent tenacity to build resistance to antibiotics and environmental stressors that allows the species to thrive in hospital environments. The continual wide use of antibiotics in medicine has been an important driver in the evolution of E. faecium becoming a highly proficient hospital pathogen.

For successful prevention and reduction of nosocomial infections with vancomycin resistant E. faecium (VREfm), it is essential to focus on reducing VREfm carriage and spread. The aim of this review is to incorporate microbiological insights of E. faecium into practical infection control recommendations, to reduce the spread of hospital-acquired VREfm (carriage and infections). The spread of VREfm can be controlled by intensified cleaning procedures, antibiotic stewardship, rapid screening of VREfm carriage focused on high-risk populations, and identification of transmission routes through accurate detection and typing methods in outbreak situations. Further, for successful management of E. faecium, continual innovation in the fields of diagnostics, treatment, and eradication is necessary.
\end{abstract}

Keywords: Enterococcus faecium, VRE, Evolution, Diagnostics, Infection control

\section{Introduction}

Enterococci were first discovered in human fecal flora in 1899. However until 1984, they were still considered part of the genus Streptococci [1]. Streptococcus faecalis was first described in 1906 when the microorganism was isolated from a patient with endocarditis. Streptococcus faecium was first detected in 1919. Later on, streptococci belonging to serogroup $\mathrm{D}$ were divided into two groups. This division was made based upon studies demonstrating differences in biochemical and differences from nucleic acid (DNA-rRNA homology studies and 16SrRNA) [2]. Streptococcus faecalis and Streptococcus faecium were placed in the enterococcus group, which more than 50 species belong [3].

\footnotetext{
* Correspondence: x.w.zhou@umcg.nl

'Department of Medical Microbiology, University of Groningen, University Medical Center Groningen, Groningen, The Netherlands

Full list of author information is available at the end of the article
}

Among the enterococci, E. faecalis and E. faecium are the main causative agents of infection in humans. In the 1970s, enterococci emerged as a leading cause of hospital-acquired infections [4]. In the past two decades, $E$. faecium has rapidly evolved as a worldwide nosocomial pathogen by successfully adapting to conditions in a nosocomial setting and acquiring resistance against glycopeptides $[5,6]$. The resistance genes against glycopeptides are organized in van operons located on mobile genetic elements (MGEs). The operons include regulatory genes controlling the expression of ligase genes conferring resistance to glycopeptides, of which the $v a n A$ and $v a n B$ genes are the most common [7].

In this review, we will first describe the historical rise of $E$. faecium infections in hospitals worldwide, followed by the subsequent emergence and epidemiological background of vancomycin resistant E. faecium (VREfm). Next, we review difficulties in VRE detection and 
infection control in the modern hospital settings, in which $E$. faecium has emerged as an important pathogen in the past 20 years. Finally, we provide practical recommendations based on these microbiological insights.

\section{The evolution of Enterococcus faecium as a hospital- adapted pathogen}

Population genetics and genomics showed that there are two distinct subpopulations of E. faecium. The first subpopulation represents commensals of the gastrointestinal (GI) tract and is usually not involved in clinical infection. The second subpopulation represents hospital-associated (HA) E. faecium lineages that cause nosocomial outbreaks and opportunistic infections in hospitalized patients. The presence of these distinct subpopulations were recognized two decades ago using amplified fragment length polymorphism (AFLP); a fingerprint-based typing method [8]. Later, sequence-based methods such as multi-locus sequence typing (MLST) and whole genome sequencing (WGS) confirmed and further described these distinct E. faecium subpopulations [9-11]. Currently, these two populations are designated as clade A and clade B. The successful HA lineages belong to a subclade of clade A, A1, previously designed as clonal complex 17 (CC-17) [12].

E. faecium isolates belonging to the HA subpopulation are characterized by ampicillin resistance and pathogenicity islands; they are also commonly associated with hospital outbreaks [11]. In addition, genome wide studies have shown that these HA isolates acquired a number of traits making them successful in the hospital environment; such as an increase in antibiotic resistance genes and virulence genes enhancing biofilm formation and colonization [13]. These adaptive traits are the result of gene acquisition and gene loss in E. faecium, which is facilitated by plasmid transfer, and through homologous recombination, mediated by insertion sequence (IS) elements. IS elements may provide homology at specific sites in the chromosome, allowing for integration of foreign genes by homologous recombination events [10]. The continuous refinement of genomic configuration, characterized by the flux and integration of successful adaptive traits, results in a selective advantage and clonal expansion of HA lineages [14] .

In the 2000's, nosocomial infections with ampicillin resistant E. faecium (AREfm) emerged in Europe, replacing E. faecalis infections [15]. In fact, European Antimicrobial Resistance Surveillance System (EARSS) data of 2002-2008 showed the largest increase (on average annually 19.3\%) in the number of positive E. faecium blood cultures compared to the increase of other pathogens as E. coli, S. aureus, S. pneumoniae and E. faecalis [16]. This emergence of $E$. faecium bloodstream infections (BSI) was also observed in surveillance data of the
University Medical Center Groningen (UMCG, The Netherlands). The ratio of positive blood cultures with E. faecium and E. faecalis in individual patients during 1998-2017 in shown in Fig. 1. While the incidence of $E$. faecalis BSI remained rather constant, the E. faecium to E. faecalis ratio changed approximately from 0.1 in 1998 to 1.6 in 2017. Hospitals in throughout Europe including Ireland, Spain, Poland, Denmark and Switzerland relate the increase of E. faecium bloodstream infections (BSI) to CC-17 clones [17-21]. Furthermore, countries outside Europe also observed increasing infections with $E$. faecium. The United States (US) observed an increase in $E$. faecium BSI from 2002, with a peak in 2010 (prevalence of 5.4\%) [22]. An overview of antimicrobial-resistant pathogens causing hospital acquired infections in the US during 2011-2014, showed an overall contribution of E. faecium of $3.7 \%$ [23], with the highest contribution in catheterassociated urinary tract infections (CAUTI). In 2014, the Australian Enterococcal Sepsis Outcome Program (AESOP) reported that a large proportion (39.9\%) of enterococcal bacteremia was caused by E. faecium [24].

\section{Emergence and epidemiology of vancomycin resistant enterococci (VRE)}

The acquisition of resistance against glycopeptides is an important landmark in the evolution of enterococci towards a highly resistant microorganism. The first reported (Van-A-type) VRE was in 1988 in France and the United Kingdom [25, 26]. Most VRE outbreaks are due to HA-vancomycin susceptible E. faecium (VSEfm) that has acquired the $v a n A$ or $v a n B$ gene $[27,28]$.

VanA-type VRE dominated the epidemiology of VRE in the US and Europe [29]. In the US, (vanA) VRE had already emerged by the 1990 s while remaining rare in hospitals throughout Europe. In both continents, the emergence of AREfm preceded the emergence of VREfm [30]. In Europe, hospital infections with AREfm started to increase from 2000, followed by an increase in VREfm [31], which was comparable to the US 20 years earlier (Fig. 2).

In contrast to the US, Europe had a large reservoir of VRE in the community by the 1990s, yet without suitable HA AREfm populations in hospitals to take up the van genes and become HA VREfm. This large reservoir of VRE in the community and farm animals were linked to the avoparcin use in husbandry [28]. Avoparcin, a glycopeptide antibiotic similar to vancomycin, had been in use since 1970 as a growth promotor in the agricultural sector in several European countries. Its use was associated with high numbers of vanA-carrying VRE in meat products and samples from livestock [32, 33]. Avoparcin was not used in the US and a community reservoir of VRE was therefore absent [34]. In the US, the rise in VRE was probably due to the extensive use of antibiotics 


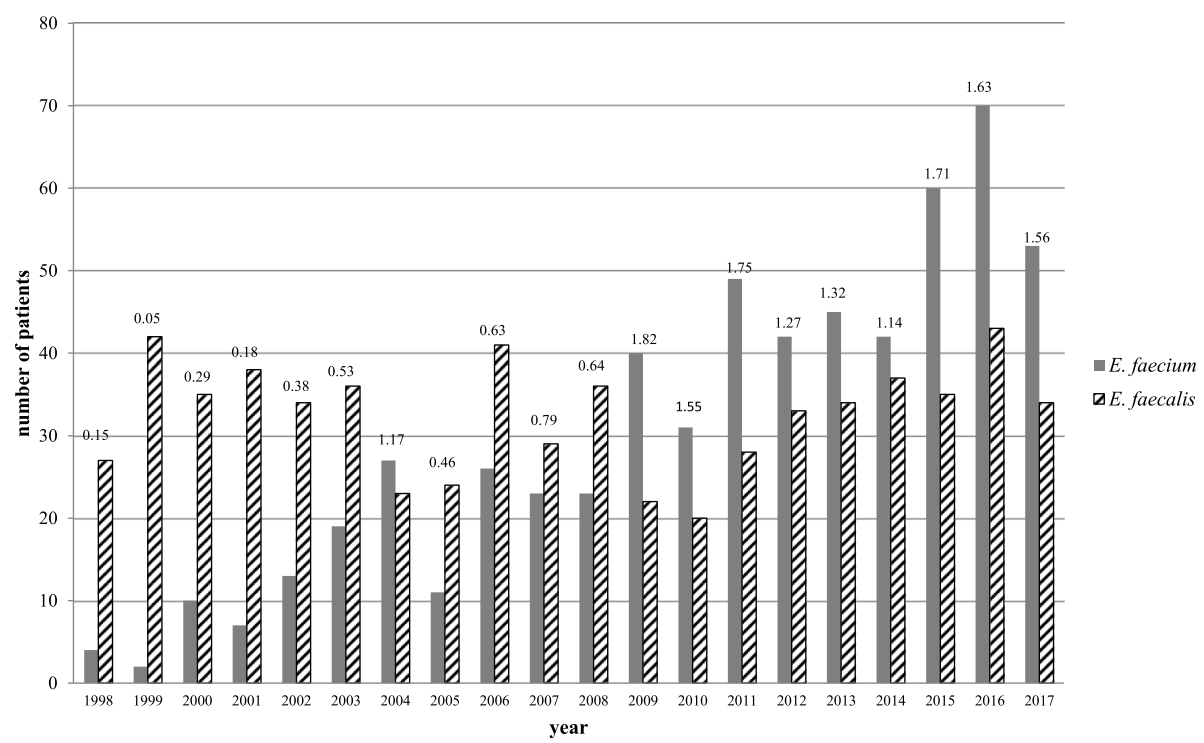

Fig. 1 Change in E. faecium to E. faecalis ratio. Number of patients with blood cultures with E. faecium and E. faecalis in individual patients and the E. faecium/E. faecalis ratio during 1998-2017 in the University Medical Center Groningen. The E. faecium to E. faecalis ratio changed approximately from 0.1 in 1998 to 1.6 in 2017

in humans [35] along with failures in infection prevention measures leading to cross transmissions [36]. Because of the potential risk of transmission of VRE or van genes from the community into the hospitals, the use of avoparcin was banned in European countries in 1997. As a result, VRE in farm animals declined rapidly. However, persistence of vancomycin resistance in E. faecium in poultry farms has been reported in several European countries [37]. It is not known to which extent these mobile genetic elements (MGEs), such as (vanA)

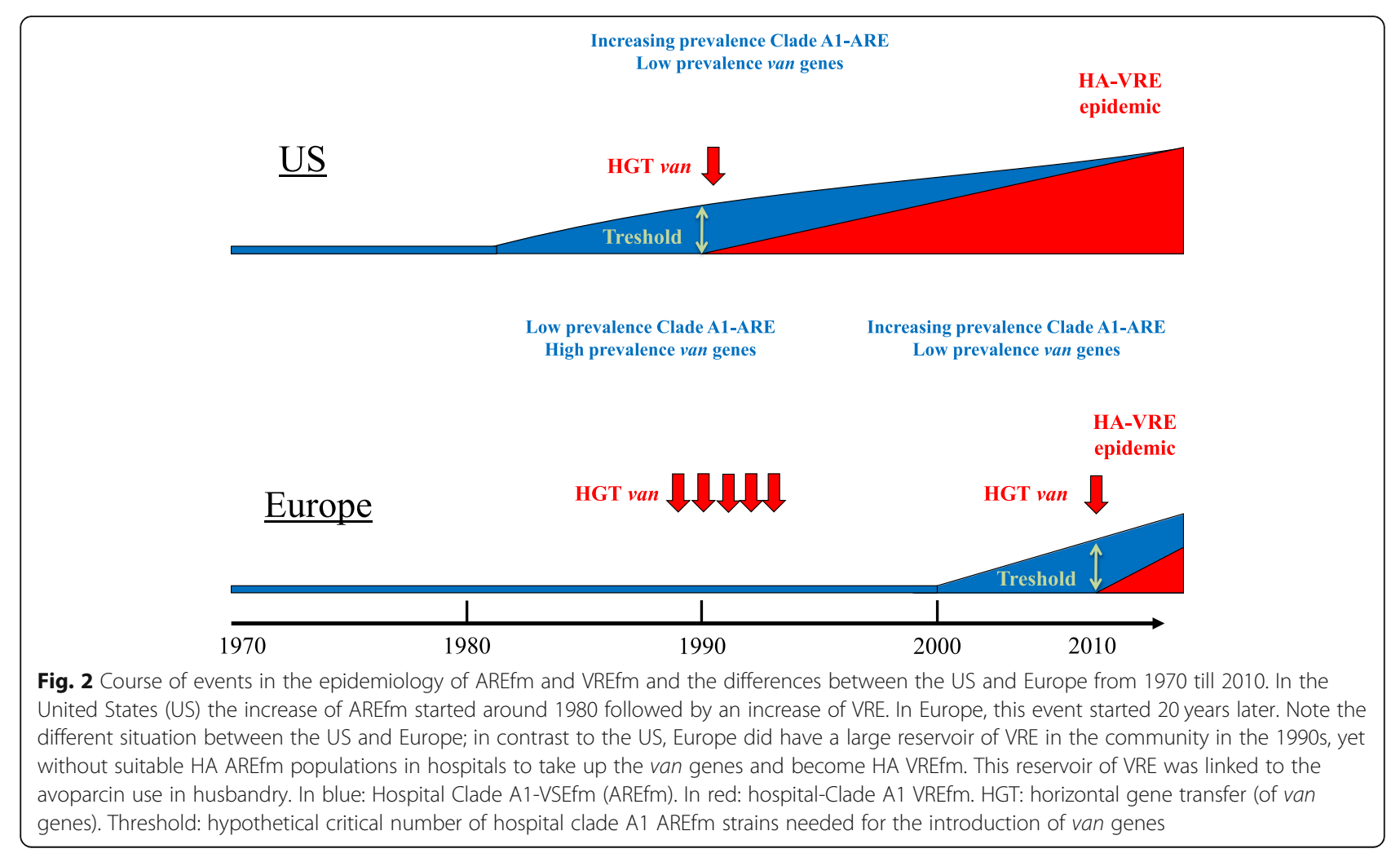


transposons are still a potential reservoir for HA VREfm [38, 39].

Data collected from 2011 to 2014 by the Centers for Disease Control and Prevention (CDC) about antibiotic resistant hospital acquired infections, showed a high but decreasing prevalence of VREfm in the US, from 80.5\% in 2011 to $75.6 \%$ in 2014 [40, 41]. Data from the European Center for Diseases and Control (ECDC) for 2016 showed variable surveillance data for VREfm between the European countries [42]. For example, the proportion of VREfm is $<1 \%$ in Sweden, Finland, the Netherlands and France; while Cyprus reports the highest proportion of $46.3 \%$ (Fig. 3). Notable increases in the proportion of VREfm has occurred in the following Eastern European countries: Romania, Latvia, Lithuania, Poland, Hungary, Slovakia, Croatia, Cyprus and Bulgaria (Fig. 4). The ECDC surveillance Atlas on Antimicrobial resistance reports VREfm proportion rates for these countries in 2016 as follows: Romania 39\%, Latvia 28.6\%, Lithuania 21.3\%, Poland 26.2\%, Hungary 22.4\%, Slovakia $26.4 \%$, Croatia $22.1 \%$, Cyprus $46.3 \%$ and Bulgaria $18.2 \%$. Little is known which lineages and van-types are involved in the significant increase of VREfm in these countries.

Importantly, this increase in $v a n B$ VRE was reported in several European countries around 2005; amongst others in Spain, Greece, Germany and France [43]. A study from Poland investigated the VRE epidemiology from 1999 to 2010 and reported an increasing prevalence of $v a n B$ VREfm [44-50]. Hospitals in Sweden had a low prevalence of VRE, with $v a n B$ VRE being detected sporadically. In 2007, outbreaks in three Swedish hospitals occurred and further clonal dissemination from $v a n B$ VRE were seen [51]. In Germany, the emerge of vanB was typically associated with MLST ST192, a lineage within CC-17 [47, 48]. In 2016, the proportion of $v a n B$ VRE was, for the first time, higher than $v a n A$ VRE [49]. .Also the Netherlands, reported a the quite significant proportion of $v a n B$ VRE. Of the 706 VRE strains that were analyzed between May 2012 and March 2016 from 42 Dutch hospitals, 363 carried the vanA gene, 340 the $v a n B$ gene, four carried both the vanA and $v a n B$ gene, and two carried the $v a n D$ gene [52].

Australia reports an increasing trend in VRE prevalence similar to many countries in Europe. The AESOP and AURA (Antimicrobial Use and Resistance in Australia) reports show a steady increase in VREfm from $36.5 \%$ in 2010 , to $48.7 \%$ in 2015 [24, 53-57]. The latest AURA report of 2017 showed the percentage of VREfm in blood cultures of 2015 ranging from 11.3 to $75 \%$ in the different states and territories of Australia [56]. The majority of these isolates were grouped into CC- 17 . Since 2010 ST203 has had a predominant place across most regions of Australia. Other predominant sequence types are ST17, ST555 and the rapidly increasing ST796, largely replacing ST203 [54]. The emergence of this new clone demonstrates the flexibility of the E. faecium genome to continuously respond and adapt to hospital and

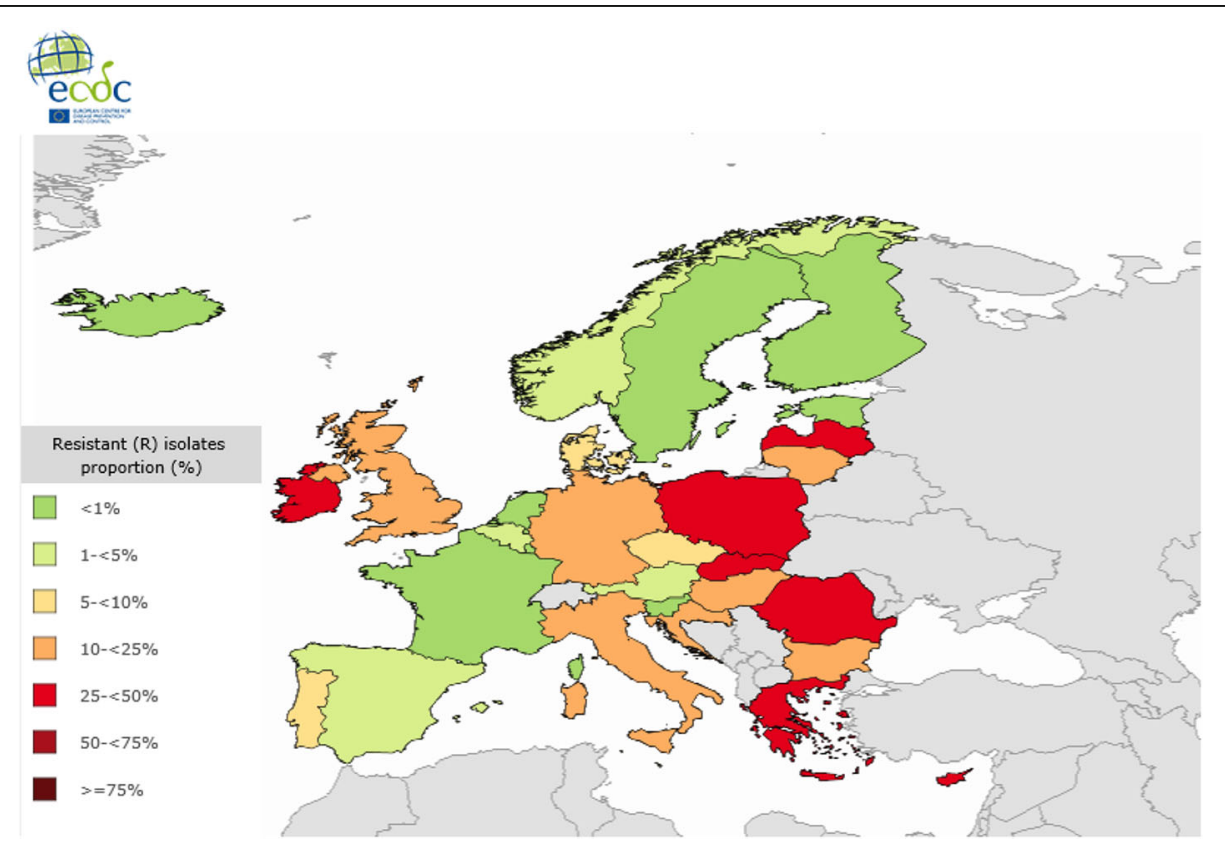

Fig. 3 Surveillance data for vancomycin resistant Enterococcus faecium in Europe. Data from the ECDC Surveillance Atlas- Antimicrobial resistance. Showing vancomycin resistance proportion rates in Enterococcus faecium in Europe for 2016. Dataset provided by ECDC based on data provided by World Health Organization (WHO) and Ministries of Health from the affected countries 


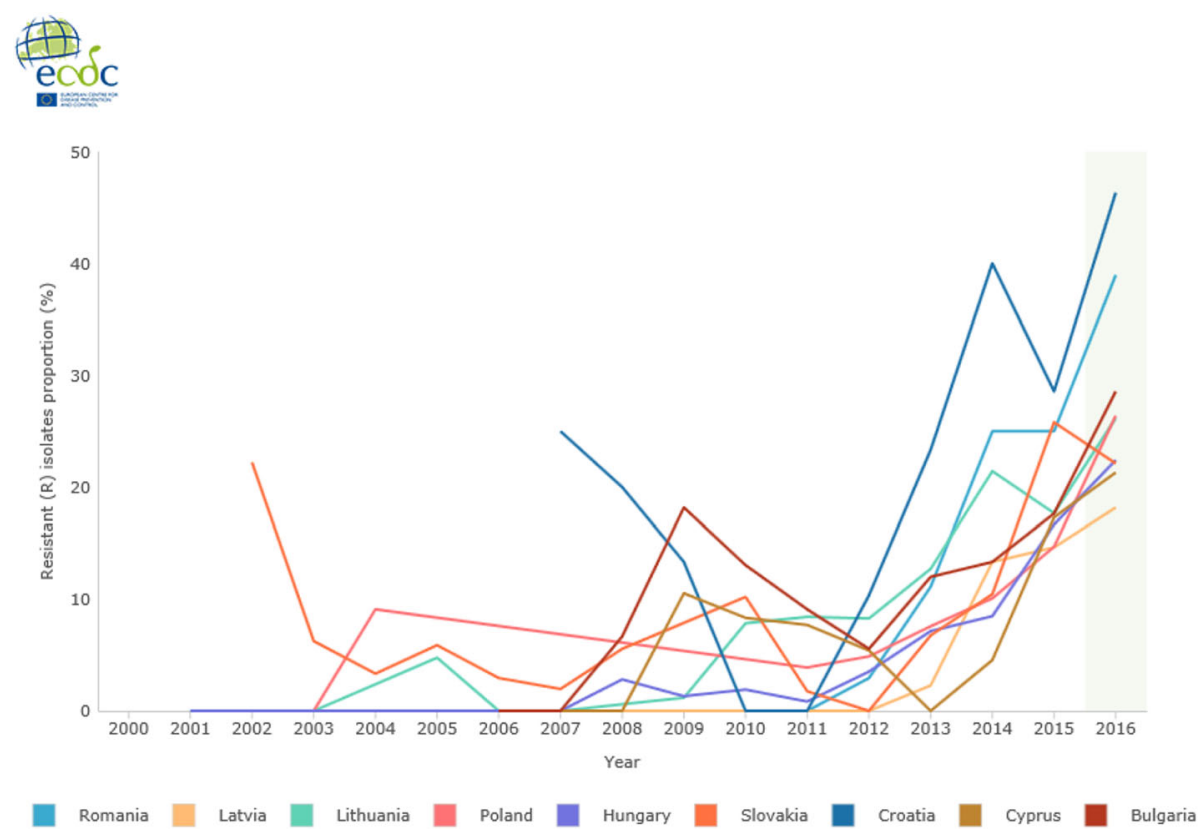

Fig. 4 vancomycin resistant Enterococcus faecium proportion rates in Eastern European countries from 2002 till 2016. Data from the ECDC Surveillance Atlas- Antimicrobial resistance. Showing the rapid increase in vancomycin resistance proportion rates in E. faecium for selected (Eastern) European countries: Romania, Latvia, Lithuania, Poland, Hungary, Slovakia, Croatia, Cyprus and Bulgaria. Dataset provided by ECDC based on data provided by WHO and Ministries of Health from the affected countries

environmental changes. VanB-type VRE dominated the epidemiology of VRE in Australia, but in recent years VanA-type VRE has emerged. In 2010, vanA VREfm was rarely detected compared to 2014 , when $18.5 \%$ of the VREfm bacteremia isolates harbored the $v a n A$ gene [58]. The recent emergence of $v a n A$ VREfm has been associated with several STs and vanA-containing plasmids. This suggests multiple introductions of the vanA operon into the circulating E. faecium clones. This could be due to sources in the community or through introduction by health-care associated travel from overseas [24].

Reports from countries in Asia, South-America, Africa, Russia and the Middle-East [59, 60] about the emergence of VREfm demonstrate the successful spread HAE. faecium lineages worldwide.

In summary, nosocomial VREfm lineages are on the rise in hospitals over all continents. Recent data showed the proportion E. faecium clinical isolates that are vancomycin resistant varies between $<1$ and $46.3 \%$ in Europe, from 75 and $80 \%$ in the US, and from 11.3 and $75 \%$ in Australia. The incorporation of MGEs such as vanB-carrying transposons into successful circulating HA-VSEfm lineages is a significant factor in the emergence of $v a n B$ VREfm. This occurs via the exchange of large chromosomal fragments, including the transposon Tn1549 carrying the $\operatorname{van} B$ resistance, between $\operatorname{van} B$ VREfm and VSEfm [61-66]. Incidentally, de novo acquisition of Tn1549 from anaerobic gut microbiota to
VSEfm may occur $[49,67]$. If these events are subsequently followed by clonal expansion, it could lead to an increase in numbers of $v a n B$ VREfm [68]. However, the success factors for the rapid dissemination of E. faecium are probably not limited to the acquisition of antibiotic resistance and virulence genes, but also to specific adaptations to hospital conditions.

\section{Difficulties to detect and control nosocomial VRE outbreaks}

E. faecium has to overcome many challenges to remain endemic in hospital environments. The spread of highly resistant microorganisms (HRMOs) in hospitals is generally limited by universal standard precautions and disinfection of patient rooms and medical equipment. In addition, the transmission can be stopped by contact isolation of patients and targeted antibiotic treatment for HRMOs. HRMOs that are undetectable may spread in the hospital and thereby have an advantage over detectable phenotypes. Diagnostic strategies may therefore have a selective role in the emergence of hospital lineages.

In literature, several evasion mechanisms has been reported in VanA-type as well as VanB-type VRE, avoiding detection by the standard recommended methods. The most common standard recommend methods used for detection of glycopeptide resistant enterococci are 
minimum inhibitory concentration (MIC) determination, disk diffusion, and the breakpoint agar method $[68,69]$.

Detection of vanB VRE can be challenging since routinely measured vancomycin MIC values can range from $\leq 0.5 \mathrm{mg} / \mathrm{L}$ to $\geq 32 \mathrm{mg} / \mathrm{L}$, as has been shown when using the Vitek2 (bioMérieux) automatic susceptibility testing system [70]. Strains that are $v a n B$ positive but are determined to be vancomycin susceptible according to the European Committee on Antimicrobial Susceptibility Testing (EUCAST) susceptibility breakpoint of $\leq 4 \mathrm{mg} / \mathrm{L}$ $[71,72]$, are at risk of spreading without detection. Percentages of these $v a n B$-positive low-level vancomycin resistant VRE strains can range from $24.5-55 \%$ in hospital outbreak settings [73]. Moreover, the sensitivity of VRE screening declines as the fecal VRE density decreases and if the culture media is assessed at $24 \mathrm{~h}$ instead of 48 $\mathrm{h}[71,72]$. This has led to the suggestion that multiple rectal swabs (up to four or five rectal swabs) are required to detect $>90-95 \%$ of the carriers [74]. The direct detection of $v a n B$ carriage by molecular detection can also be compromised by many false positive results due to $\operatorname{van} B$ genes in non-enterococcal anaerobic bacteria present in the gut $[75,76]$. An enriched inoculated broth containing metronidazole can be used in a polymerase chain reaction (PCR)-based VRE screening. Additionally, cut-off cycle threshold $(\mathrm{Ct})$-values can be adjusted to differentiate between detection of van genes carried by VRE and interfering signals from the anaerobic flora [77-81].

VanA VRE detection can be complicated by variations in the phenotype. Van genes are located in an operon that include regulatory genes controlling their expression. The expression of resistance to the glycopeptide teicoplanin can be heterogeneous, corresponding into a VanB-phenotype [82]. The presence of vanS (sensor) and $v a n R$ (regulator) regulatory genes in the $v a n A$ cassette are essential for the expression of glycopeptide resistance. Some isolates can test vancomycin and teicoplanin susceptible because of major nucleotide deletions or even absence of vanS and vanR genes in the vanA transposon [83] or due to insertion of $I S$ elements in the coding regions of the vanA transposon $[84,85]$. The vanA-positive enterococci that are phenotypically susceptible to vancomycin are also termed vancomycinvariable enterococci (VVE) [86]. The VVE are in 'stealth mode' and are at risk to spread without detection. In case of major deletions, or complete absence of vanS $/ R$ genes and thus being non-functional genes, strains will probably not revert under vancomycin therapy. However, in case of small deletions in the $v a n R / S$ region, or if the region is silenced by $I S$ elements, VVE strains can revert into vancomycin resistant strains upon vancomycin therapy [87], which can lead to treatment failure.

VRE may also evade detection by molecular diagnostics because multiple distinct gene clusters may confer resistance to vancomycin. Nine different van ligase genes in enterococci have been described ( $\operatorname{van} A, B, C, D, E, G$, $L, M$, and $N$ ) [86, 88]. Since VRE outbreaks are mainly due to vanA and/or vanB VREfm [89-92], PCR-based methods most often only target $v a n A$ and $v a n B$, but not the other types of van genes. VRE harboring mobile genetic islands with $v a n D$ are sporadically found in patients, but no dissemination of these islands has yet been detected $[28,93]$. However, its prevalence may be underreported since the $v a n D$ gene is not detected by routine molecular diagnostics.

\section{Infection control measures}

Enterococci are highly tenacious microorganisms by nature. Compared to their ancestors, enterococci acquired traits that have led to an increased tolerance to desiccation and starvation, which make them resistant to environmental stresses similar to modern hospitals [94]. To survive in a hospital environment the adaptive traits of high tenacity and resistance to disinfection procedures are important for the hospital VRE lineages, allowing them to survive for many years in a hospital environment [95]. Enterococci are therefore excellent indicators of environmental contamination [96, 97]. Enterococci are often isolated from high-contact points such as bed rails, over-bed tables, blood-pressure cuffs, alarm buttons, toilet seats and door handles [98]. As a consequence, transmission of enterococci not only occurs directly through contaminated hands of health care workers, patients, or visitors, but also indirectly through contaminated environmental surfaces [99]. Contaminated surfaces represent hidden reservoirs, from which enterococci may re-emerge and colonize patients that are subsequently admitted to the contaminate room [7]. In attempts to eradicate persistent reservoirs with VRE, intensified cleaning measures like targeted cleaning of environmental surfaces using high concentrations of sodium chloride or decontamination with hydrogen peroxide vapor should be used $[96,100]$.

Enterococci can be tolerant to low concentrations of chemicals such as alcohol and chlorine [101, 102]. After the intensified introduction of alcohol-based hand rubs in Australian hospitals, the use of hand alcohols increased during 2001-2015. When investigating HA E. faecium strains isolated from Australian hospitals between 1998 and 2015, there was a significant increase in isopropanolol tolerance over time [103]. Although the alcohol tolerance experiments were established with a concentration of $23 \%$, lower than the $70 \%$ which is used in hand alcohols, these tolerant E. faecium isolates still survived better than the less tolerant isolates after the $70 \%$ isopropanolol surface disinfection. This exemplifies how E. faecium can adapt to environmental changes such as an increased use of hand alcohols. Inter- 
individual differences in hand hygiene compliance between healthcare workers could lead to a variety in VREfm reductions on hands. In case of limited reduction, there might be an unforeseen spread of VREfm.

The characteristic of heat-resistance is an important adaptive trait of enterococci. In early studies, the exceptionality of heat-resistance in enterococci had been reported in investigating pasteurization of dairy products [104]. A study comparing heat resistance of VSE versus VRE showed that some vancomycin-resistant isolates even survived exposure to 80 degrees Celsius for several minutes [105]. This is of particular relevance for infection control practices, since disinfection procedures of bedpans regularly include heating at 80 degrees for 1 $\min$.

Several infection prevention strategies have been advised by the CDC Hospital Infection Control Practices Advisory Committee (HICPAC) for controlling VRE such as; prudent use of vancomycin, education programs for hospital staff, early detection and reporting of VRE by clinical microbiology laboratories, and isolation precautions and implementation of infection-control measures to prevent transmission of VRE including contact isolation for VRE-positive patients [103]. It is difficult to state which infection prevention measure by itself has the highest impact. The implementation of hand hygiene and decreasing environmental contamination by cleaning measures have a significant impact on reducing the spread of VRE [106]. However, single infection prevention measures often fail to have a real effect on reducing VRE rates. A multifaceted program implementing several guidelines, such as advised by the HICPAC, are therefore often needed to observe a clear reduction in VRE rates [107, 108].

Antibiotic use, especially metronidazole, vancomycin and cephalosporins are risk factors for VRE acquisition $[109,110]$. Treatment with antibiotics that have activity against anaerobic bacteria can lead to a profound proliferation of VRE in the GI tract and subsequent BSI [111114]. Ceftriaxone usage has also been associated with VRE BSIs [111, 115]. This demonstrates that the stringent use of antibiotics to reduce the selective pressure is important and has successfully been applied in controlling ongoing VRE outbreaks [116].

Since a patient with an infection caused by VRE could be the tip of an iceberg $[117,118]$ active surveillance is needed to detect VRE-carriage in patients in high-risk units [119]. Screening patients transferred from foreign countries with high VRE prevalence is also another important infection prevention measure.

\section{Molecular typing of VRE}

In VRE outbreak investigations, rapid and accurate typing is required to investigate the genetic relatedness between patients' isolates. This information is essential to demonstrate nosocomial transmission and whether it is needed to enhance infection prevention measures. Rapid typing followed by infection prevention measures can lead to rapid control of nosocomial spread [75]. In Table 1, we summarized common used VRE typing methods and accompanying characteristics; reproducibility, ease of performance, data interpretation, ease of data exchange and costs.

WGS is increasingly used in (VRE) outbreak analysis [120] and provides the highest discriminatory power. In addition, WGS offers the possibilities to perform pangenome analysis to even enhance the assessment of genetic relatedness $[48,121,122]$. Additionally, a wide range of information can be extracted from WGS data such as MLST, core-genome (cg) MLST, whole-genome (wg) MLST data, virulence factors, resistance genes, plasmids and other genetic markers. However, there are some challenges to overcome to make it more accessible in daily routine clinical microbiology and outbreak analysis. Most important are the standardization and validation of procedures [123] and the interpretation of data [124]. The ease of data interpretation depends on the type of analysis to perform and which tools are available [125]. For example, cgMLST data can easily be extracted from WGS data by several in-house and commercially software packages. Compared to MLST, cgMLST has a higher discriminatory power in distinguishing genetically related and unrelated $E$. faecium isolates [126-128]. The advantage of cgMLST over single-nucleotide polymorphism (SNP)-based methods is that the data can easily be compared, stored and shared in web-based databases that can be interrogated (http://www.cgmlst.org/ncs/ schema/991893/). Importantly, if VRE outbreaks are caused by horizontal transfer of MGEs encoding vancomycin-resistance, studying the molecular epidemiology of these MGEs by specifically analyzing the various transposons encoding $v a n A$ or $v a n B$ gene clusters is essential. The use of WGS facilitates detailed analysis of variation in these transposons. These transposon analyses will enhance the resolution of used typing methods and provide better insight in VRE outbreaks [129].

\section{Conclusion and future perspectives}

In the future, it will be a challenge to withstand the spread of VREfm. A rapid and ongoing emergence of VREfm has been observed in countries in Central and Eastern Europe. Variances within same countries along with large regional differences have been observed in this rise of VREfm infections. This is underlined by the regional differences in VREfm proportions in German and Dutch regions. In 2016, the lowest proportion in Germany was reported in the region of North-West Germany (5.9\%), which is in contrast with the 
Table 1 Vancomycin resistant enterococci typing methods and accompanying characteristics

\begin{tabular}{|c|c|c|c|c|c|c|}
\hline Method & MLVA & MLST & PFGE & cgMLST & WGS & Transposon analysis \\
\hline Principle & $\begin{array}{l}\text { Fragment length } \\
\text { of variable tandem } \\
\text { repeat loci }\end{array}$ & $\begin{array}{l}\text { Sequences of } \\
\text { multiple house } \\
\text { keeping genes }\end{array}$ & $\begin{array}{l}\text { DNA based } \\
\text { macro restriction } \\
\text { analysis }\end{array}$ & $\begin{array}{l}\text { Genome-wide } \\
\text { gene-by-gene } \\
\text { approach of } 1423 \\
\text { genes on allelic } \\
\text { level }\end{array}$ & $\begin{array}{l}\text { Whole genome } \\
\text { analysis }\end{array}$ & $\begin{array}{l}\text { Sequences of transposon } \\
\text { content and integration }\end{array}$ \\
\hline Reproducibility & High & High & Medium & Excellent & Excellent & Excellent \\
\hline Ease of performance & Very easy & Easy & Laborious & Easy & Easy & Easy \\
\hline Data interpretation & Easy-moderate & Easy & Difficult & Easy & Various & Moderate \\
\hline $\begin{array}{l}\text { Ease of data } \\
\text { exchange }\end{array}$ & Easy & Easy & Difficult & Easy & Possible & Possible \\
\hline Costs & Low & Medium & Medium & $\begin{array}{l}\text { High, extracted } \\
\text { from WGS }\end{array}$ & High & $\begin{array}{l}\text { High, extracted from } \\
\text { WGS }\end{array}$ \\
\hline $\begin{array}{l}\text { Discriminatory } \\
\text { power }\end{array}$ & Low & Medium & High & Excellent & Excellent & Additional \\
\hline
\end{tabular}

MLVA Multiple Locus Variable Number of Tandem Repeat Analysis, MLST Multi-locus Sequence Typing, PFGE Pulsed-field gel electrophoresis, cgMLST core-genome MLST, WGS whole-genome sequencing

Table 2 Recommendations for infection control and detection methods of VRE

\begin{tabular}{|c|c|c|}
\hline Traits of Enterococcus faecium & Implications for infection control & Recommendations \\
\hline $\begin{array}{l}\text { High tenacity and intrinsic } \\
\text { resistance to environmental } \\
\text { stress }\end{array}$ & $\begin{array}{l}\text { - Prolonged survival in hospital environment. } \\
\text { - High survival to desiccation and starvation. } \\
\text { - Resistance to heat and disinfection procedures. }\end{array}$ & $\begin{array}{l}\text { - Intensified cleaning procedures, including intensified } \\
\text { cleaning procedures and prolonged disinfection } \\
\text { procedures [132]. } \\
\text { - Implementation of infection-control measures to prevent } \\
\text { transmission of VRE, including isolation precautions for } \\
\text { VRE-positive patients [97, 101, 103]. } \\
\text { - Education programs for hospital staff, including hand } \\
\text { hygiene to prevent further transmission [106]. } \\
\text { - Environmental cultures in (uncontrolled) VRE outbreaks } \\
\text { and surveillance cultures after disinfections. }\end{array}$ \\
\hline Intrinsic resistance antibiotics & $\begin{array}{l}\text { - Outgrowth under antibiotic pressure. } \\
\text { - Prone to become pan-resistant. }\end{array}$ & $\begin{array}{l}\text { - Antibiotic stewardship, especially prudent use of } \\
\text { vancomycin (reduce emergence of VRE) [106] and } \\
\text { metronidazole (reduce outgrowth of VRE) [106]. } \\
\text { - Surveillance and controlling of VRE-carriage in } \\
\text { hospitals [133, 134]. }\end{array}$ \\
\hline Genome plasticity & $\begin{array}{l}\text { - Continuously adaptation and refinement in response } \\
\text { to environmental changes. } \\
\text { - Development of resistance to newer antibiotics and } \\
\text { disinfectants in the future. }\end{array}$ & $\begin{array}{l}\text { - Continuous awareness and surveillance to detect } \\
\text { resistance to newer antibiotics and disinfectants. } \\
\text { - Further research and development of antimicrobial } \\
\text { targets for the treatment of MDR E. faecium [106]. }\end{array}$ \\
\hline Diagnostic evasion & $\begin{array}{l}\text { - Phenotypes of evolutionary successful HA VRE lineages } \\
\text { that evade detection by standard recommended } \\
\text { methods for detection of glycopeptide resistance in } \\
\text { E. faecium } \\
\text { - Difficulties in detecting VRE-carriage due to low fecal } \\
\text { densities }\end{array}$ & $\begin{array}{l}\text { - Active surveillance cultures to detect VRE-carriage in } \\
\text { patients at high-risk units and patients transferred from } \\
\text { foreign countries with high VRE prevalence [135]. } \\
\text { - Multiple rectal samples (four to five), are needed to } \\
\text { detect the majority of carriers (>90-95\%) [106]. } \\
\text { - Get knowledge of the local epidemiology of VRE and } \\
\text { vancomycin MICs in own hospital. } \\
\text { - Early and accurate detection and reporting of VRE by } \\
\text { clinical microbiology laboratories [75, 76]. } \\
\text { - For rapid screening of VRE carriage, a combination of } \\
\text { selective enrichment broths and molecular detection } \\
\text { increases the sensitivity [106]. } \\
\text { - Use of selective (chromogenic) agar in the laboratory } \\
\text { detection of VRE [82]. } \\
\text { - Vancomycin disk diffusion according to EUCAST in the } \\
\text { detection of vancomycin-resistance in VRE [136]. } \\
\text { - Genotypic testing of invasive vancomycin-susceptible } \\
\text { enterococci by PCR [137]. }\end{array}$ \\
\hline $\begin{array}{l}\text { Common origin of hospital } \\
\text { lineages in early twentieth } \\
\text { century (CC-17) }\end{array}$ & - Typing difficulties during VRE outbreaks. & $\begin{array}{l}\text { - Rapid and accurate typing is needed to take adequate } \\
\text { infection prevention measures in VRE outbreaks. } \\
\text { - Preferably a highly discriminatory typing method like } \\
\text { cgMLST or WGS, ideally combined with transposon } \\
\text { analysis should be used in VRE outbreak analysis. }\end{array}$ \\
\hline
\end{tabular}


proportion in the North-East (9.5\%), South-East (16.2\%), and South-West (17.6\%) [68, 69]. The proportion of VRE in the Dutch Northern-East region bordering with North-West Germany remained very low between 2013 and 2016. Among these two regions, collaborative crossborder INTERREG-projects focusing on prevention of the spread of highly-resistant microorganisms are ongoing. Although there is no conclusive explanation for the variations in the German regions, surveillance and outbreak management strategies, antibiotic stewardship policies [130], and differences in patient traffic from high prevalence countries may be important factors. In some countries, VRE infection control policies focuses only on patients with infections, while other countries patients belonging to high-risk populations are also screened for VRE-carriage as recommended by HICPAC [131]. VRE infections are commonly preceded by VRE-carriage, as described in our review. Early detection of carriage may prevent the spread and reduce the number infections. In the Netherlands there have been many outbreaks with patients carrying VRE. These outbreaks were controlled in an early phase, and thereby the proportion of infections with VRE is still low in the Netherlands.

Thus, if the goal of a hospital is to prevent VREfm infections, special attention is required to reduce the VREfm spread by screening for VREfm-carriage. Other important factors are the role of hospital environment contamination by VREfm and the challenges in detection and typing of VREfm. We summarize recommendations described in literature and/or by guidelines in Table 2 . Many of the recommendations follow directly from the microbiological traits of E. faecium as we reviewed. So far, these recommendations have shown to be successful in the control of VREfm in the Netherlands. However, these measures are very expensive and require a lot of effort from medical (molecular) microbiologists and infection control specialists [106]. Adequate VREfm diagnostics and typing can be difficult, as described in this review. Innovations in the detection and typing of VREfm are required to overcome these difficulties. Development of better selective media, PCRs with higher specificity, or rapid point of care tests are needed to detect VREfm more efficiently. A promising development is the use of clone-specific PCRs, which might be helpful to detect and control VREfm outbreaks caused by specific clones [118]. This method combines typing and detection in a rapid and cost-effective manner [138].

It is a point of debate whether these efforts are worthwhile to control the spread of VREfm. The attributable mortality of the currently successful VREfm lineages is mainly due to inappropriate (empirical) antibiotics rather than additional virulence of vancomycin resistance [139]. However, treatment options are limited in VREfm, since E. faecium is intrinsically resistant to many antibiotic classes. Resistance to several last-line enterococcal drugs like linezolid, daptomycin, tigecycline, and quinopristindalfopristin have already emerged [140-142]. Further research and development of antimicrobial targets is needed for the treatment of multidrug resistant (MDR) E. faecium [143-146]. Development of new antibiotics is expensive, requires time, and has a risk of rapid development of resistance to these new drugs. Therefore, it is important to use the current available antibiotics prudently and optimize adherence to hygiene precautions to prevent the patient-to-patient spread of VREfm resistant to these lastline antibiotics. It may be wise to reduce the spread of VREfm by surveillance in high risk populations. However, in many hospitals this might be difficult to realize. Capacity building programs and structural financial support for hospitals would be needed to implement efficient nosocomial screening for VREfm-carriage and subsequent infection control measures. Cross-border collaborations may prove useful in the implementation of such programs and have previously shown to be successful in decreasing the methicillin resistant Staphylococcus aureus (MRSA) prevalence in the Dutch-German Euregion [135].

\section{Abbreviations}

AESOP: Australian Enterococcal Sepsis Outcome Program; AREfm: Ampicillin resistant E. faecium; AURA: Antimicrobial Use and Resistance in Australia; BSI: Bloodstream infections; CC-17: Clonal complex 17; CDC: Centers for Disease Control and Prevention; Ct: Cycle threshold; EARSS: European Antimicrobial Resistance Surveillance System; EUCAST: European Committee on Antimicrobial Susceptibility Testing; Gl: Gastrointestinal; HA: Hospital adapted; HICPAC: Hospital Infection Control Practices Advisory Committee; HRMO: Highly resistant microorganism; IS: Insertion sequence; MDR: Multidrug resistant; MIC: Minimum inhibitory concentration; MGE: Mobile genetic element; MLST: Multi-locus sequence typing; cgMLST: core-genome MLST; wgMLST: whole-genome MLST; MLVA: Multiple Locus Variable Number of Tandem Repeat Analysis; MRSA: Methicillin resistant Staphylococcus aureus; PFGE: Pulsed-field gel electrophoresis; PCR: Polymerase chain reaction; SNP: Single-nucleotide polymorphism; UMCG: University Medical Center Groningen; US: United States; VRE: Vancomycin resistant enterococci; VREfm: Vancomycin resistant $E$. faecium; VSEfm: Vancomycin susceptible E. faecium; WE: Vancomycin-variable enterococci; WGS: Whole genome sequencing; WHO: World Health Organization

\section{Acknowledgements}

We would like to thank Mariëtte Lokate and Matthijs Berends for providing the data of the proportion of vancomycin resistant isolates (\%) in Enterococcus faecium in the North-East Netherlands. We thank Jan Arends for providing the data of the positive blood cultures with E. faecalis and E. faecium.

Authors' contributions

All authors contributed in writing the manuscript. All authors read and approved the final manuscript.

\section{Funding}

This study was partly supported by the Interreg Va-funded project EurHealth1 Health (InterregVa/202085), part of a Dutch-German cross-border network supported by the European Union, the German Federal States of NordrheinWestfalen and Niedersachsen and the Dutch Ministry of Health, Wellbeing and Sport (WWS). 


\section{Availability of data and materials}

All data generated or analysed during this study are included in this published article.

\section{Ethics approval and consent to participate} Not applicable.

\section{Consent for publication}

Not applicable.

\section{Competing interests}

John Rossen consults for IDbyDNA. All other authors declare no conflicts of interest. IDbyDNA did not have any influence on interpretation of reviewed data and conclusions drawn, nor on drafting of the manuscript and no support was obtained from them.

\section{Author details}

'Department of Medical Microbiology, University of Groningen, University Medical Center Groningen, Groningen, The Netherlands. ${ }^{2}$ Department of Medical Microbiology, University Medical Center Utrecht, Utrecht, The Netherlands.

Received: 25 July 2019 Accepted: 2 July 2020

Published online: 10 August 2020

\section{References}

1. Murray BE. The life and times of the Enterococcus. Clin Microbiol Rev. 1990; 3(1):46-65.

2. Schleifer, Kilpper-Balz. Transfer of Streptococcus faecalis and Streptococcus faecium to the Genus Enterococcus norn. rev. as Enterococcus faecalis comb. nov. and Enterococcus faecium comb. nov. Int J Syst Bacteriol Jan. 1984;34:31-4.

3. Parte AC. LPSN--list of prokaryotic names with standing in nomenclature. Nucleic Acids Res. 2014;42(Database issue):D613-6.

4. Gilmore MS, Lebreton F, van Schaik W. Genomic transition of enterococci from gut commensals to leading causes of multidrug-resistant hospital infection in the antibiotic era. Curr Opin Microbiol. 2013;16(1):10-6.

5. Top J, Willems R, Bonten M. Emergence of CC17 Enterococcus faecium: from commensal to hospital-adapted pathogen. FEMS Immunol Med Microbiol. 2008:52(3):297-308.

6. Bonten MJ, Willems R, Weinstein RA. Vancomycin-resistant enterococci: why are they here, and where do they come from? Lancet Infect Dis. 2001;1(5): 314-25.

7. Arias CA, Murray BE. The rise of the Enterococcus: beyond vancomycin resistance. Nat Rev Microbiol. 2012;10(4):266-78.

8. Willems RJ, Top J, van Den Braak N, van Belkum A, Endtz H, Mevius D, et al. Host specificity of vancomycin-resistant Enterococcus faecium. J Infect Dis. 2000;182(3):816-23.

9. Galloway-Pena J, Roh JH, Latorre M, Qin X, Murray BE. Genomic and SNP Analyses Demonstrate a Distant Separation of the Hospital and CommunityAssociated Clades of Enterococcus faecium. PLoS One. 2012;7(1):e30187.

10. Leavis HL, Willems RJ, van Wamel WJ, Schuren FH, Caspers MP, Bonten MJ. Insertion sequence-driven diversification creates a globally dispersed emerging multiresistant subspecies of E. faecium. PLoS Pathog. 2007:3(1):e7.

11. Willems RJ, Top J, van Santen M, Robinson DA, Coque TM, Baquero F, et al. Global spread of vancomycin-resistant Enterococcus faecium from distinct nosocomial genetic complex. Emerg Infect Dis. 2005;11(6):821-8.

12. Willems RJ, Top J, van Schaik W, Leavis H, Bonten M, Siren J, et al. Restricted gene flow among hospital subpopulations of Enterococcus faecium. MBio. 2012;3(4):e00151-12.

13. Gao W, Howden BP, Stinear TP. Evolution of virulence in Enterococcus faecium, a hospital-adapted opportunistic pathogen. Curr Opin Microbiol. 2017:41:76-82.

14. Baquero F. From pieces to patterns: evolutionary engineering in bacterial pathogens. Nat Rev Microbiol. 2004;2(6):510-8.

15. Top J, Willems R, Blok H, de Regt M, Jalink K, Troelstra A, et al. Ecological replacement of Enterococcus faecalis by multiresistant clonal complex 17 Enterococcus faecium. Clin Microbiol Infect. 2007;13(3):316-9.

16. de Kraker ME, Jarlier V, Monen JC, Heuer OE, van de Sande N, Grundmann $\mathrm{H}$. The changing epidemiology of bacteraemias in Europe: trends from the
European Antimicrobial Resistance Surveillance System. Clin Microbiol Infect. 2012;3.

17. Gudiol C, Ayats J, Camoez M, Dominguez MA, Garcia-Vidal C, Bodro M, et al. Increase in bloodstream infection due to vancomycin-susceptible Enterococcus faecium in cancer patients: risk factors, molecular epidemiology and outcomes. PLoS One. 2013;8(9):e74734.

18. Pinholt M, Ostergaard C, Arpi M, Bruun NE, Schonheyder HC, Gradel KO, et al. Incidence, clinical characteristics and 30-day mortality of enterococcal bacteraemia in Denmark 2006-2009: a population-based cohort study. Clin Microbiol Infect. 2014;20(2):145-51.

19. Gawryszewska I, Zabicka D, Bojarska K, Malinowska K, Hryniewicz W, Sadowy E. Invasive enterococcal infections in Poland: the current epidemiological situation. Eur J Clin Microbiol Infect Dis. 2016;35(5):847-56.

20. Weisser M, Capaul S, Dangel M, Elzi L, Kuenzli E, Frei R, et al. Additive effect of Enterococcus faecium on Enterococcal bloodstream infections: a 14-year study in a Swiss tertiary hospital. Infect Control Hosp Epidemiol. 2013;34(10): 1109-12.

21. Ryan L, O'Mahony E, Wrenn C, FitzGerald S, Fox U, Boyle B, et al. Epidemiology and molecular typing of VRE bloodstream isolates in an Irish tertiary care hospital. J Antimicrob Chemother. 2015;70(10): 2718-24.

22. Mendes RE, Castanheira M, Farrell DJ, Flamm RK, Sader HS, Jones RN. Longitudinal (2001-14) analysis of enterococci and VRE causing invasive infections in European and US hospitals, including a contemporary (201013) analysis of oritavancin in vitro potency. J Antimicrob Chemother. 2016; 71(12):3453-8.

23. Weiner LM, Webb AK, Limbago B, Dudeck MA, Patel J, Kallen AJ, et al Antimicrobial-Resistant Pathogens Associated With HealthcareAssociated Infections: Summary of Data Reported to the National Healthcare Safety Network at the Centers for Disease Control and Prevention, 2011-2014. Infect Control Hosp Epidemiol. 2016;37(11): $1288-301$.

24. Coombs GW, Daley DA, Thin Lee Y, Pang S, Pearson JC, Robinson JO, et al. Australian Group on Antimicrobial Resistance Australian Enterococcal Sepsis Outcome Programme annual report, 2014. Commun Dis Intell Q Rep. 2016; 40(2):E236-43.

25. Leclercq R, Derlot E, Duval J, Courvalin P. Plasmid-mediated resistance to vancomycin and teicoplanin in Enterococcus faecium. N Engl J Med. 1988; 319(3):157-61.

26. Uttley $\mathrm{AH}$, Collins $\mathrm{CH}$, Naidoo J, George RC. Vancomycin-resistant enterococci. Lancet. 1988;1(8575-6):57-8.

27. Freitas AR, Sousa C, Novais C, Silva L, Ramos H, Coque TM, et al. Rapid detection of high-risk Enterococcus faecium clones by matrix-assisted laser desorption ionization time-of-flight mass spectrometry. Diagn Microbiol Infect Dis. 2017:87(4):299-307.

28. Werner G, Coque TM, Hammerum AM, Hope R, Hryniewicz W, Johnson A, et al. Emergence and spread of vancomycin resistance among enterococci in Europe. Euro Surveill. 2008;13(47):19046

29. Cetinkaya Y, Falk P, Mayhall CG. Vancomycin-resistant enterococci. Clin Microbiol Rev. 2000;13(4):686-707.

30. Grayson ML, Eliopoulos GM, Wennersten CB, Ruoff KL, De Girolami PC, Ferraro MJ, et al. Increasing resistance to beta-lactam antibiotics among clinical isolates of Enterococcus faecium: a 22-year review at one institution. Antimicrob Agents Chemother. 1991;35(11):2180-4.

31. Jones RN, Sader HS, Erwin ME, Anderson SC. Emerging multiply resistant enterococci among clinical isolates. I. Prevalence data from 97 medical center surveillance study in the United States. Enterococcus Study Group. Diagn Microbiol Infect Dis. 1995;21(2):85-93.

32. Endtz HP, van den Braak N, van Belkum A, Kluytmans JA, Koeleman JG, Spanjaard $L$, et al. Fecal carriage of vancomycin-resistant enterococci in hospitalized patients and those living in the community in The Netherlands. J Clin Microbiol. 1997;35(12):3026-31.

33. van den Braak $N$, van Belkum $A$, van Keulen $M$, Vliegenthart J, Verbrugh $H A$, Endtz HP. Molecular characterization of vancomycin-resistant enterococci from hospitalized patients and poultry products in The Netherlands. J Clin Microbiol. 1998;36(7):1927-32.

34. Klare I, Badstubner D, Konstabel C, Bohme G, Claus H, Witte W. Decreased incidence of VanA-type vancomycin-resistant enterococci isolated from poultry meat and from fecal samples of humans in the community after discontinuation of avoparcin usage in animal husbandry. Microb Drug Resist. 1999:5(1):45-52 
35. Coque TM, Tomayko JF, Ricke SC, Okhyusen PC, Murray BE. Vancomycin-resistant enterococci from nosocomial, community, and animal sources in the United States. Antimicrob Agents Chemother. 1996;40(11):2605-9.

36. Kirst HA, Thompson DG, Nicas TI. Historical yearly usage of vancomycin. Antimicrob Agents Chemother. 1998:42(5):1303-4.

37. Bonten MJ, Hayden MK, Nathan C, van Voorhis J, Matushek M, Slaughter S, et al. Epidemiology of colonisation of patients and environment with vancomycin-resistant enterococci. Lancet. 1996;348(9042):1615-9.

38. Sorum M, Johnsen PJ, Aasnes B, Rosvoll T, Kruse $H$, Sundsfjord A, et al. Prevalence, persistence, and molecular characterization of glycopeptideresistant enterococci in Norwegian poultry and poultry farmers 3 to 8 years after the ban on avoparcin. Appl Environ Microbiol. 2006;72(1): 516-21.

39. Bortolaia V, Mander M, Jensen LB, Olsen JE, Guardabassi L. Persistence of vancomycin resistance in multiple clones of Enterococcus faecium isolated from Danish broilers 15 years after the ban of avoparcin. Antimicrob Agents Chemother. 2015;59(5):2926-9.

40. Nilsson O. Vancomycin resistant enterococci in farm animals - occurrence and importance. Infect Ecol Epidemiol. 2012;2. https://doi.org/10.3402/iee. v2i0.16959 Epub 2012 Apr 19.

41. Johnsen PJ, Osterhus Jl, Sletvold H, Sorum M, Kruse H, Nielsen K, et al. Persistence of animal and human glycopeptide-resistant enterococci on two Norwegian poultry farms formerly exposed to avoparcin is associated with a widespread plasmid-mediated vanA element within a polyclonal enterococcus faecium population. Appl Environ Microbiol. 2005;71(1):159-68.

42. Centers for Disease Control and Prevention (CDC). Antibiotic resistant bacteria, healthcare associated infections, data 2011-2014: https://gis.cdc. gov/grasp/PSA/MapView.html.

43. European Centre for Disease Prevention and Control (ECDC). Data from the ECDC Surveillance Atlas - Antimicrobial resistance: https://ecdc.europa.eu/ en/antimicrobial-resistance/surveillance-and-disease-data/data-ecdc. Reports 2005-2019.

44. Nebreda T, Oteo J, Aldea C, Garcia-Estebanez C, Gastelu-Iturri J, Bautista V, et al. Hospital dissemination of a clonal complex 17 vanB2-containing Enterococcus faecium. J Antimicrob Chemother. 2007;59(4):806-7.

45. Valdezate S, Labayru C, Navarro A, Mantecon MA, Ortega M, Coque TM, et al. Large clonal outbreak of multidrug-resistant CC17 ST17 Enterococcus faecium containing Tn5382 in a Spanish hospital. J Antimicrob Chemother. 2009;63(1):17-20.

46. Protonotariou E, Dimitroulia E, Pournaras S, Pitiriga V, Sofianou D, Tsakris A. Trends in antimicrobial resistance of clinical isolates of Enterococcus faecalis and Enterococcus faecium in Greece between 2002 and 2007. J Hosp Infect. 2010;75(3):225-7.

47. Sivertsen A, Billstrom $H$, Melefors $O$, Liljequist BO, Wisell KT, Ullberg M, et al. A multicentre hospital outbreak in Sweden caused by introduction of a vanB2 transposon into a stably maintained pRUM-plasmid in an Enterococcus faecium ST192 clone. PLoS One. 2014:9(8):e103274.

48. Lytsy B, Engstrand L, Gustafsson A, Kaden R. Time to review the gold standard for genotyping vancomycin-resistant enterococci in epidemiology: Comparing whole-genome sequencing with PFGE and MLST in three suspected outbreaks in Sweden during 2013-2015. Infect Genet Evol. 2017; $54: 74-80$.

49. Bender JK, Kalmbach A, Fleige C, Klare I, Fuchs S, Werner G. Population structure and acquisition of the vanB resistance determinant in German clinical isolates of Enterococcus faecium ST192. Sci Rep. 2016;6:21847.

50. Bourdon N, Fines-Guyon M, Thiolet JM, Maugat S, Coignard B, Leclercq R, et al. Changing trends in vancomycin-resistant enterococci in French hospitals, 2001-08. J Antimicrob Chemother. 2011;66(4):713-21.

51. Sadowy E, Gawryszewska I, Kuch A, Zabicka D, Hryniewicz W. The changing epidemiology of VanB Enterococcus faecium in Poland. Eur J Clin Microbiol Infect Dis. 2018;13:927-36.

52. Robert Koch Institut. Eigenschaften, Häufigkeit und Verbreitung von Vancomycinresistenten Enterokokken (VRE) in Deutschland https://www.rki. de/DE/Content/Infekt/EpidBull/Archiv/2017/Ausgaben/46_17.pdf?_blob= publicationFile Epidemiologisches Bulletin November 2017(46):519-530.

53. NethMap 2016. NethMap 2016: Consumption of antimicrobial agents and antimicrobial resistance among medically important bacteria in the Netherlands 2015. https://www.rivm.nl/dsresource?objectid=752059cb-4 dfa-42ec-a013-60bc21 e52508\&type=org\&disposition=inline.
54. Australian Commission on Safety and Quality in Health Care (ACSQHC). AURA 2017: second Australian report on antimicrobial use and resistance in human health. Sydney: ACSQHC; 2017.

55. Coombs GW, Pearson JC, Christiansen K, Gottlieb T, Bell JM, George N, et al. Australian Group on Antimicrobial Resistance Enterococcus Surveillance Programme annual report, 2010. Commun Dis Intell Q Rep. 2013;37(3):E199209.

56. Coombs GW, Pearson JC, Le T, Daly DA, Robinson JO, Gottlieb T, et al. Australian Enterococcal Sepsis Outcome Progamme, 2011. Commun Dis Intell Q Rep. 2014;38(3):E247-52.

57. Coombs GW, Pearson JC, Daly DA, Le TT, Robinson JO, Gottlieb T, et al. Australian Enterococcal Sepsis Outcome Programme annual report, 2013. Commun Dis Intell Q Rep. 2014;38(4):E320-6.

58. Buultjens AH, Lam MM, Ballard S, Monk IR, Mahony AA, Grabsch EA, et al. Evolutionary origins of the emergent ST796 clone of vancomycin resistant Enterococcus faecium. PeerJ. 2017;5:e2916.

59. van Hal SJ, Espedido BA, Coombs GW, Howden BP, Korman TM, Nimmo GR, et al. Polyclonal emergence of vanA vancomycin-resistant Enterococcus faecium in Australia. J Antimicrob Chemother. 2017;72(4):998-1001.

60. Coombs GW, Daley D, Pearson JC, Ingram PR. A change in the molecular epidemiology of vancomycin resistant enterococci in Western Australia. Pathology. 2014;46(1):73-5.

61. Brilliantova AN, Kliasova GA, Mironova AV, Tishkov VI, Novichkova GA, Bobrynina VO, et al. Spread of vancomycin-resistant Enterococcus faecium in two haematological centres in Russia. Int J Antimicrob Agents. 2010;35(2): 177-81.

62. Khan MA, Northwood JB, Loor RG, Tholen AT, Riera E, Falcon M, et al. High prevalence of ST-78 infection-associated vancomycin-resistant Enterococcus faecium from hospitals in Asuncion, Paraguay. Clin Microbiol Infect. 2010; 16(6):624-7.

63. Khan MA, van der Wal M, Farrell DJ, Cossins L, van Belkum A, Alaidan A, et al. Analysis of VanA vancomycin-resistant Enterococcus faecium isolates from Saudi Arabian hospitals reveals the presence of clonal cluster 17 and two new Tn1546 lineage types. J Antimicrob Chemother. 2008;62(2):279-83.

64. Ochoa SA, Escalona G, Cruz-Cordova A, Davila LB, Saldana Z, CazaresDomimguez $\mathrm{V}$, et al. Molecular analysis and distribution of multidrugresistant Enterococcus faecium isolates belonging to clonal complex 17 in a tertiary care center in Mexico City. BMC Microbiol. 2013;13:291-2180-13-291.

65. Hsieh YC, Lee WS, Ou TY, Hsueh PR. Clonal spread of CC17 vancomycinresistant Enterococcus faecium with multilocus sequence type 78 (ST78) and a novel ST444 in Taiwan. Eur J Clin Microbiol Infect Dis. 2010;29(1):2530.

66. Aamodt H, Mohn SC, Maselle S, Manji KP, Willems R, Jureen R, et al. Genetic relatedness and risk factor analysis of ampicillin-resistant and high-level gentamicin-resistant enterococci causing bloodstream infections in Tanzanian children. BMC Infect Dis. 2015;15:107-015-0845-8.

67. van Hal SJ, Ip CL, Ansari MA, Wilson DJ, Espedido BA, Jensen SO, et al. Evolutionary dynamics of Enterococcus faecium reveals complex genomic relationships between isolates with independent emergence of vancomycin resistance. Microb Genom. 2016;2(1). https://doi.org/10. 1099/mgen.0.000048.

68. Howden BP, Holt KE, Lam MM, Seemann T, Ballard S, Coombs GW, et al. Genomic insights to control the emergence of vancomycin-resistant enterococci. MBio. 2013;4(4). https://doi.org/10.1128/mBio.00412-13.

69. Zhou X, Chlebowicz MA, Bathoorn E, Rosema S, Couto N, Lokate M, et al. Elucidating vancomycin-resistant Enterococcus faecium outbreaks: the role of clonal spread and movement of mobile genetic elements. J Antimicrob Chemother. 2018;73(12):3259-67.

70. EUCAST subcommittee for detection of resistance mechanisms and specific resistances of clinical and/or epidemiological importance: EUCAST guidelines for detection of resistance mechanisms and specific resistances of clinical and/or epidemiological importance. 2017.

71. Zhou X, Friedrich AW, Bathoorn E. Diagnostic Evasion of Highly-Resistant Microorganisms: A Critical Factor in Nosocomial Outbreaks. Front Microbiol. 2017;8:2128

72. Werner G, Klare I, Fleige C, Geringer U, Witte W, Just HM, et al. Vancomycinresistant vanB-type Enterococcus faecium isolates expressing varying levels of vancomycin resistance and being highly prevalent among neonatal patients in a single ICU. Antimicrob Resist Infect Control. 2012;1(1):21.

73. European Committee on Antimicrobial Susceptibility Testing 2014. The European Committee on Antimicrobial Susceptibility Testing. Breakpoint 
tables for interpretation of MICs and zone diameters. Version 7.1, 2017. http://www.eucast.org.

74. Wijesuriya TM, Perry P, Pryce T, Boehm J, Kay I, Flexman J, et al. Low vancomycin MICs and fecal densities reduce the sensitivity of screening methods for vancomycin resistance in Enterococci. J Clin Microbiol. 2014; 52(8):2829-33.

75. Pearman JW. 2004 Lowbury Lecture: the Western Australian experience with vancomycin-resistant enterococci - from disaster to ongoing control. J Hosp Infect. 2006;63(1):14-26.

76. Sinnige JC, Willems RJL, Ruijs GJHM, Mascini E, Arends JP, Troelstra A. NVMM Guideline HRMO VRE; 2015

77. Ballard SA, Pertile KK, Lim M, Johnson PD, Grayson ML. Molecular characterization of vanB elements in naturally occurring gut anaerobes. Antimicrob Agents Chemother. 2005;49(5):1688-94.

78. Ballard SA, Grabsch EA, Johnson PD, Grayson ML. Comparison of three $P C R$ primer sets for identification of $\operatorname{vanB}$ gene carriage in feces and correlation with carriage of vancomycin-resistant enterococci: interference by vanB-containing anaerobic bacilli. Antimicrob Agents Chemother. 2005;49(1):77-81.

79. Domingo MC, Huletsky A, Bernal A, Giroux R, Boudreau DK, Picard FJ, et al. Characterization of a Tn5382-like transposon containing the vanB2 gene cluster in a Clostridium strain isolated from human faeces. J Antimicrob Chemother. 2005;55(4):466-74.

80. Graham M, Ballard SA, Grabsch EA, Johnson PD, Grayson ML. High rates of fecal carriage of nonenterococcal vanB in both children and adults. Antimicrob Agents Chemother. 2008;52(3):1195-7.

81. Stinear TP, Olden DC, Johnson PD, Davies JK, Grayson ML. Enterococcal vanB resistance locus in anaerobic bacteria in human faeces. Lancet. 2001; 357(9259):855-6.

82. Zhou X, Arends JP, Kampinga GA, Ahmad HM, Dijkhuizen B, van Barneveld $P$, et al. Evaluation of the Xpert vanA/vanB assay using enriched inoculated broths for direct detection of vanB vancomycin-resistant Enterococci. J Clin Microbiol. 2014;52(12):4293-7.

83. Park IJ, Lee WG, Shin JH, Lee KW, Woo GJ. VanB phenotype-vanA genotype Enterococcus faecium with heterogeneous expression of teicoplanin resistance. J Clin Microbiol. 2008;46(9):3091-3.

84. Szakacs TA, Kalan L, McConnell MJ, Eshaghi A, Shahinas D, McGeer A, et al. Outbreak of vancomycin-susceptible Enterococcus faecium containing the wild-type vanA gene. J Clin Microbiol. 2014;52(5):1682-6.

85. Gagnon S, Levesque S, Lefebvre B, Bourgault AM, Labbe AC, Roger M. vanAcontaining Enterococcus faecium susceptible to vancomycin and teicoplanin because of major nucleotide deletions in Tn1546. J Antimicrob Chemother. 2011;66(12):2758-62.

86. Sivertsen A, Pedersen T, Larssen KW, Bergh K, Ronning TG, Radtke A, et al. A Silenced vanA Gene Cluster on a Transferable Plasmid Caused an Outbreak of Vancomycin-Variable Enterococci. Antimicrob Agents Chemother. 2016; 60(7):4119-27.

87. Kohler P, Eshaghi A, Kim HC, Plevneshi A, Green K, Willey BM, et al. Prevalence of vancomycin-variable Enterococcus faecium (WE) among vanA-positive sterile site isolates and patient factors associated with WE bacteremia. PLoS One. 2018;13(3):e0193926.

88. Thaker MN, Kalan L, Waglechner N, Eshaghi A, Patel SN, Poutanen S, et al. Vancomycin-variable enterococci can give rise to constitutive resistance during antibiotic therapy. Antimicrob Agents Chemother. 2015;59(3):1405-10.

89. Courvalin P. Vancomycin resistance in gram-positive cocci. Clin Infect Dis. 2006:42(Suppl 1):S25-34.

90. Xu X, Lin D, Yan G, Ye X, Wu S, Guo Y, et al. vanM, a new glycopeptide resistance gene cluster found in Enterococcus faecium. Antimicrob Agents Chemother. 2010;54(11):4643-7.

91. Boyd DA, Willey BM, Fawcett D, Gillani N, Mulvey MR. Molecular characterization of Enterococcus faecalis N06-0364 with low-level vancomycin resistance harboring a novel D-Ala-D-Ser gene cluster, vanL. Antimicrob Agents Chemother. 2008;52(7):2667-72

92. Lebreton F, Depardieu F, Bourdon N, Fines-Guyon M, Berger P, Camiade S, et al. D-Ala-d-Ser VanN-type transferable vancomycin resistance in Enterococcus faecium. Antimicrob Agents Chemother. 2011;55(10):4606-12.

93. Freitas AR, Tedim AP, Francia MV, Jensen LB, Novais C, Peixe L, et al. Multilevel population genetic analysis of vanA and vanB Enterococcus faecium causing nosocomial outbreaks in 27 countries (1986-2012). J Antimicrob Chemother. 2016;71(12):3351-66.
94. Top J, Sinnige JC, Brouwer EC, Werner G, Corander J, Severin JA, et al. Identification of a Novel Genomic Island Associated with vanD-Type Vancomycin Resistance in Six Dutch Vancomycin-Resistant Enterococcus faecium Isolates. Antimicrob Agents Chemother. 2018;62(3). https://doi.org/ 10.1128/AAC.01793-17 Print 2018 Mar.

95. Lebreton F, Manson AL, Saavedra JT, Straub TJ, Earl AM, Gilmore MS. Tracing the Enterococci from Paleozoic Origins to the Hospital. Cell. 2017;169(5): 849-861.e13.

96. Wagenvoort JH, De Brauwer El, Penders RJ, van der Linden CJ, Willems RJ, Top J, et al. Environmental survival of vancomycin-sensitive ampicillinresistant Enterococcus faecium (AREfm). Eur J Clin Microbiol Infect Dis. 2015; 34(9):1901-3.

97. Dancer SJ. Controlling hospital-acquired infection: focus on the role of the environment and new technologies for decontamination. Clin Microbiol Rev. 2014;27(4):665-90.

98. Boehm AB, Sassoubre LM. Enterococci as Indicators of Environmental Fecal Contamination. In: Gilmore MS, Clewell DB, Ike Y, Shankar N, editors. Enterococci: From Commensals to Leading Causes of Drug Resistant Infection Boston; 2014.

99. de Regt MJ, van der Wagen LE, Top J, Blok HE, Hopmans TE, Dekker AW, et al. High acquisition and environmental contamination rates of CC17 ampicillin-resistant Enterococcus faecium in a Dutch hospital. J Antimicrob Chemother. 2008;62(6):1401-6.

100. Wagenvoort JH, De Brauwer El, Penders RJ, Willems RJ, Top J, Bonten MJ. Environmental survival of vancomycin-resistant Enterococcus faecium. J Hosp Infect. 2011;77(3):282-3.

101. Grabsch EA, Mahony AA, Cameron DR, Martin RD, Heland M, Davey P, et al. Significant reduction in vancomycin-resistant enterococcus colonization and bacteraemia after introduction of a bleach-based cleaning-disinfection programme. J Hosp Infect. 2012;82(4):234-42.

102. Passaretti CL, Otter JA, Reich NG, Myers J, Shepard J, Ross T, et al. An evaluation of environmental decontamination with hydrogen peroxide vapor for reducing the risk of patient acquisition of multidrug-resistant organisms. Clin Infect Dis. 2013;56(1):27-35.

103. Bradley CR, Fraise AP. Heat and chemical resistance of enterococci. J Hosp Infect. 1996;34(3):191-6.

104. Pidot SJ, Gao W, Buultjens AH et al. Increasing tolerance of hospital Enterococcus faecium to hand-wash alcohols. 2016. bioRxiv preprint posted online. https://doi.org/10.1101/053728.

105. McAuley CM, Gobius KS, Britz ML, Craven HM. Heat resistance of thermoduric enterococci isolated from milk. Int J Food Microbiol. 2012; 154(3):162-8.

106. Centers for Disease Control and Prevention. Recommendations for preventing the spread of vancomycin resistance. Recommendations of the Hospital Infection Control Practices Advisory Committee (HICPAC). MMWR Recomm Rep. 1995:44(RR-12):1-13.

107. De Angelis G, Cataldo MA, De Waure C, Venturiello S, La Torre G, Cauda R, et al. Infection control and prevention measures to reduce the spread of vancomycin-resistant enterococci in hospitalized patients: a systematic review and meta-analysis. J Antimicrob Chemother. 2014;69(5):1185-92.

108. Hayden MK, Bonten MJ, Blom DW, Lyle EA, van de Vijver DA, Weinstein RA. Reduction in acquisition of vancomycin-resistant enterococcus after enforcement of routine environmental cleaning measures. Clin Infect Dis. 2006:42(11):1552-60

109. Shaikh ZH, Osting CA, Hanna HA, Arbuckle RB, Tarr JJ, Raad II. Effectiveness of a multifaceted infection control policy in reducing vancomycin usage and vancomycin-resistant enterococci at a tertiary care cancer centre. J Hosp Infect. 2002;51(1):52-8

110. Montecalvo MA, Jarvis WR, Uman J, Shay DK, Petrullo C, Rodney K, et al. Infection-control measures reduce transmission of vancomycin-resistant enterococci in an endemic setting. Ann Intern Med. 1999;131(4):269-72.

111. Donskey CJ, Chowdhry TK, Hecker MT, Hoyen CK, Hanrahan JA, Hujer AM, et al. Effect of antibiotic therapy on the density of vancomycin-resistant enterococci in the stool of colonized patients. N Engl J Med. 2000;343(26):1925-32.

112. Edmond MB, Ober JF, Weinbaum DL, Pfaller MA, Hwang T, Sanford MD, et al. Vancomycin-resistant Enterococcus faecium bacteremia: risk factors for infection. Clin Infect Dis. 1995;20(5):1126-33.

113. Donskey CJ, Hanrahan JA, Hutton RA, Rice LB. Effect of parenteral antibiotic administration on the establishment of colonization with vancomycinresistant Enterococcus faecium in the mouse gastrointestinal tract. J Infect Dis. 2000;181(5):1830-3. 
114. Tornieporth NG, Roberts RB, John J, Hafner A, Riley LW. Risk factors associated with vancomycin-resistant Enterococcus faecium infection or colonization in 145 matched case patients and control patients. Clin Infect Dis. 1996;23(4):767-72.

115. Ubeda C, Taur Y, Jenq RR, Equinda MJ, Son T, Samstein M, et al. Vancomycin-resistant Enterococcus domination of intestinal microbiota is enabled by antibiotic treatment in mice and precedes bloodstream invasion in humans. J Clin Invest. 2010;120(12):4332-41.

116. McKinnell JA, Kunz DF, Chamot E, Patel M, Shirley RM, Moser SA, et al. Association between vancomycin-resistant Enterococci bacteremia and ceftriaxone usage. Infect Control Hosp Epidemiol. 2012;33(7):718-24.

117. Iosifidis E, Evdoridou I, Agakidou E, Chochliourou E, Protonotariou E, Karakoula K, et al. Vancomycin-resistant Enterococcus outbreak in a neonatal intensive care unit: epidemiology, molecular analysis and risk factors. Am J Infect Control. 2013;41(10):857-61.

118. Frakking FNJ, Bril WS, Sinnige JC, Klooster JEV, de Jong BAW, van Hannen EJ, et al. Recommendations for the successful control of a large outbreak of vancomycin-resistant Enterococcus faecium (VRE) in a non-endemic hospital setting. J Hosp Infect. 2018.

119. Cattoir V, Leclercq R. Twenty-five years of shared life with vancomycinresistant enterococci: is it time to divorce? J Antimicrob Chemother. 2013; 68(4):731-42.

120. Deplano A, Denis O, Nonhoff C, Rost F, Byl B, Jacobs F, et al. Outbreak of hospital-adapted clonal complex-17 vancomycin-resistant Enterococcus faecium strain in a haematology unit: role of rapid typing for early control. J Antimicrob Chemother. 2007;60(4):849-54.

121. Mahony AA, Buultjens AH, Ballard SA, Grabsch EA, Xie S, Seemann T, et al. Vancomycin-resistant Enterococcus faecium sequence type 796 - rapid international dissemination of a new epidemic clone. Antimicrob Resist Infect Control. 2018:7:44-018-0335-z eCollection 2018

122. Brodrick HJ, Raven KE, Harrison EM, Blane B, Reuter S, Torok ME, et al. Whole-genome sequencing reveals transmission of vancomycin-resistant Enterococcus faecium in a healthcare network. Genome Med. 2016;8(1):4015-0259-7.

123. McNally A, Oren Y, Kelly D, Pascoe B, Dunn S, Sreecharan T, et al. Combined Analysis of Variation in Core, Accessory and Regulatory Genome Regions Provides a Super-Resolution View into the Evolution of Bacterial Populations. PLoS Genet. 2016;12(9):e1006280.

124. Tagini F, Greub G. Bacterial genome sequencing in clinical microbiology: a pathogen-oriented review. Eur J Clin Microbiol Infect Dis. 2017;36(11):200720.

125. Schurch AC, Arredondo-Alonso S, Willems RJL, Goering RV. Whole genome sequencing options for bacterial strain typing and epidemiologic analysis based on single nucleotide polymorphism versus gene-by-gene-based approaches. Clin Microbiol Infect. 2018;24(4):350-4.

126. Deurenberg RH, Bathoorn E, Chlebowicz MA, Couto N, Ferdous M, GarciaCobos S, et al. Application of next generation sequencing in clinical microbiology and infection prevention. J Biotechnol. 2017;243:16-24.

127. Rossen JWA, Friedrich AW, Moran-Gilad J, ESCMID Study Group for Genomic and Molecular Diagnostics (ESGMD). Practical issues in implementing whole-genome-sequencing in routine diagnostic microbiology. Clin Microbiol Infect. 2017.

128. Quainoo S, Coolen JPM, van Hijum SAFT, Huynen MA, Melchers WJG, van Schaik W, et al. Whole-Genome Sequencing of Bacterial Pathogens: the Future of Nosocomial Outbreak Analysis. Clin Microbiol Rev. 2017;30(4): 1015-63.

129. de Been M, Pinholt M, Top J, Bletz S, Mellmann A, van Schaik W, et al. A core genome MLST scheme for high-resolution typing of Enterococcus faecium. J Clin Microbiol. 2015;23(12):3788-97.

130. Available at: https://ars.rki.de/Content/Database/ResistanceOverview.aspx Access dates 2013-2016.

131. Remschmidt C, Schroder C, Behnke M, Gastmeier P, Geffers C, Kramer TS Continuous increase of vancomycin resistance in enterococci causing nosocomial infections in Germany - 10 years of surveillance. Antimicrob Resist Infect Control. 2018;7:54-018-0353-x eCollection 2018.

132. Jurke A, Kock R, Becker K, Thole S, Hendrix R, Rossen J, et al. Reduction of the nosocomial meticillin-resistant Staphylococcus aureus incidence density by a region-wide search and follow-strategy in forty German hospitals of the EUREGIO, 2009 to 2011. Euro Surveill. 2013;18(36):pii=20579.

133. Buffie CG, Pamer EG. Microbiota-mediated colonization resistance against intestinal pathogens. Nat Rev Immunol. 2013;13(11):790-801.
134. Ubeda C, Bucci V, Caballero S, Djukovic A, Toussaint NC, Equinda M, et al. Intestinal microbiota containing Barnesiella species cures vancomycin-resistant Enterococcus faecium colonization. Infect Immun. 2013;81(3):965-73.

135. van Harten RM, Willems RJL, Martin NI, Hendrickx APA. Multidrug-Resistant Enterococcal Infections: New Compounds, Novel Antimicrobial Therapies? Trends Microbiol. 2017;25(6):467-79.

136. Klare I, Fleige C, Geringer U, Witte W, Werner G. Performance of three chromogenic VRE screening agars, two Etest((R)) vancomycin protocols, and different microdilution methods in detecting vanB genotype Enterococcus faecium with varying vancomycin MICs. Diagn Microbiol Infect Dis. 2012; 74(2):171-6.

137. Hegstad K, Giske CG, Haldorsen B, Matuschek E, Schonning K, Leegaard TM, et al. Performance of the EUCAST disk diffusion method, the CLSI agar screen method, and the Vitek 2 automated antimicrobial susceptibility testing system for detection of clinical isolates of Enterococci with low- and medium-level VanB-type vancomycin resistance: a multicenter study. J Clin Microbiol. 2014;52(5):1582-9.

138. Zhou K, Lokate M, Deurenberg RH, Tepper M, Arends JP, Raangs EG, et al. Use of whole-genome sequencing to trace, control and characterize the regional expansion of extended-spectrum beta-lactamase producing ST15 Klebsiella pneumoniae. Sci Rep. 2016;6:20840.

139. Sigrid Rosema, Monika Chlebowicz, Mariëtte Lokate, Alexander W. Friedrich, Erik Bathoorn, John W. A. Rossen. Tailor-made diagnostics to differentiate two simultaneously occurring vancomycin-resistant Enterococcus faecium outbreaks caused by different clones of ST117. ECCMID, O0136. 2018 Madrid, Spain.

140. Prematunge C, MacDougall C, Johnstone J, Adomako K, Lam F, Robertson J, et al. VRE and VSE Bacteremia Outcomes in the Era of Effective VRE Therapy: A Systematic Review and Meta-analysis. Infect Control Hosp Epidemiol. 2016:37(1):26-35.

141. Cheah AL, Spelman T, Liew D, Peel T, Howden BP, Spelman D, et al. Enterococcal bacteraemia: factors influencing mortality, length of stay and costs of hospitalization. Clin Microbiol Infect. 2013;19(4):E181-9.

142. Zasowski EJ, Claeys KC, Lagnf AM, Davis SL, Rybak MJ. Time Is of the Essence: The Impact of Delayed Antibiotic Therapy on Patient Outcomes in Hospital-Onset Enterococcal Bloodstream Infections. Clin Infect Dis. 2016; 62(10):1242-50.

143. Wang Y, LV Y, Cai J, Schwarz S, Cui L, Hu Z, et al. A novel gene, optrA, that confers transferable resistance to oxazolidinones and phenicols and its presence in Enterococcus faecalis and Enterococcus faecium of human and animal origin. J Antimicrob Chemother. 2015;70(8):2182-90.

144. Diaz L, Tran TT, Munita JM, Miller WR, Rincon S, Carvajal LP, et al. Wholegenome analyses of Enterococcus faecium isolates with diverse daptomycin MICs. Antimicrob Agents Chemother. 2014;58(8):4527-34.

145. Fiedler S, Bender JK, Klare I, Halbedel S, Grohmann E, Szewzyk U, et al. Tigecycline resistance in clinical isolates of Enterococcus faecium is mediated by an upregulation of plasmid-encoded tetracycline determinants tet $(L)$ and tet(M). J Antimicrob Chemother. 2016;71(4):871-81.

146. Donabedian SM, Perri MB, Vager D, Hershberger E, Malani P, Simjee S, et al. Quinupristin-dalfopristin resistance in Enterococcus faecium isolates from humans, farm animals, and grocery store meat in the United States. J Clin Microbiol. 2006:44(9):3361-5.

\section{Publisher's Note}

Springer Nature remains neutral with regard to jurisdictional claims in published maps and institutional affiliations.

\section{Ready to submit your research? Choose BMC and benefit from:}

- fast, convenient online submission

- thorough peer review by experienced researchers in your field

- rapid publication on acceptance

- support for research data, including large and complex data types

- gold Open Access which fosters wider collaboration and increased citations

- maximum visibility for your research: over $100 \mathrm{M}$ website views per year

At $\mathrm{BMC}$, research is always in progress.

Learn more biomedcentral.com/submissions 